the War. They certainly make striking provisions for the non-vocational education of their alumni and are concerned with their students' welfare to an extent formerly unknown.

However much a technical high school may reflect the local special demands of the regional industries, such as the Ruhr industries at Aachen or the chemical firms at the Rhineland schools or at Hanover, the technical high schools have never permitted, it seems, the wider aspects of their educational function to be forgotten. In their programmes of broader education they give prominence to-day to social and eivic issues, particularly with reference to the scientist's and engineer's responsibility in society. Despite signs of reactionary students' elubs of the old type re-emerging, it must be said that the forms taken over from British university systems are all steps in the direction of closer per. sonal contact with the students. The relevant features in this respect are to-day comprehensive students' guilds, in place of the old politically orientated corporations ; the encouragement of small tutorials and informal discussions; and the gradual creation of residential facilities.

\title{
LUBRICATION AND WEAR
}

T WENTY years ago the Institution of Mechanical Engineers convened, under the chairmanship of the late Dr. H. J. Gough, an international discussion on "Lubrication and Lubricants" at which more than a hundred papers were contributed from leading authorities throughout the world. The Conference itself and its proceedings, published in two volumes in 1937, marked the first serious recognition of lubrication as a field of both practical and theoretical importance. As a result of the great success of these discussions, the Institution-in conjunction with its American sister organization and other bodies. decided to hold a similar conference on lubrication with the emphasis on wear. An organizing committee was set up under Dr. D. Clayton in 1955, and the results of its efforts were shown in the Conference on Lubrication and Wear held in London during October 1-3. More than one hundred papers were again contributed and delegates from sixteen foreign countries ranging-alphabetically-from Australia to Yugoslavia were present. It was a particularly pleasant opportunity to renew acquaintance with American workers in the field and to make contact with the large and representative Russian delegation. Unfortunately some of their papers did not arrive in time for publication, but they were given ample opportunity to describe their work in the discussion periods. Most of the sessions were held in the magnificent circular conference room at Church House and a pastel October sun, sustained through. out the Conference, brought out the grace and dignity of the surrounding buildings. Across the bend in the river the glittering dome of St. Paul's looked no less impressive than it did to Wordsworth.

The Conference proceedings were very much down to earth and were extremely efficiently--if somewhat severely-organized. Each section was preceded by a review of the main papers and there was wide. spread admiration for the effective way in which this was done.

Hydrodynamic lubrication. Perhaps the most striking impression of the papers covered in this field is the extent to which new work often contrining important innovations continues to emerge. Even in the subject of journal bearings where, as Prof. D. G. Christopherson (Imperial College of Science and Technology, London) pointed out in his review article, one would have thought that after seventy years the subject would have been fully explored, the papers at the Conference provided ample evidence that this was not so. Many of the new problems have arisen or become more discernible as a result of the increasing tendency to impose higher speeds and loads on bearings : or if they were hinted at briefly in the discussion in 1937, they have received fuller and more critical analysis. Thus it is now clear that the earlier classical theories of hydrodynamic lubrication are no longer strictly valid, as is shown by some recent studies of cavitation in the hydrodynamic film in the regions of low pressure. To some extent the detailed behaviour may also be complicated by the wettability of the surfaces by the lubricant. For example, it has been found that the friction on a bearing operating in the fully hydrodynamic region may be reduced by 20 per cent by coating the surface with an oleophobic layer. Again, the temperature developed in the oil film has now been explored and it seems, surprisingly, as if the temperature arouncl the circumference is almost uniform. This is often aided by turbulent flow in the film at very high speeds. Thus the bearing may be considered to behave as a 'mixer' containing a heat-source to which a stream of cool oil is being added and from which an equal stream of oil at the mixer temperature is being withdrawn. This provides a useful empirical simplification which facilitates bearing design : here a new feature has emerged since 1937, namely, the use of electronic computers. So far as general design is concerned it is interesting to see the general change in bearing dimensions that have become accepted in high-speed operations. The short axial length of modern bearings is a new development that has many practical advantages. Another development of increasing importance is the use of air as a lubricant in high-speed hydrodynamic bearings.

A serious practical problem dealt with in a review article by B. L. Newkirk of Schenectady is that of journal-bearing instability, such as shaft-whipping and oil-whirl. Here a beneficial modification in the strueture of the main moving elements is not always possible and in many cases the troubles may be overcome by some special feature of the bearing design. It is possible that more use might be made in future of the quasi-elastic and damping capacity of the oil film itself. 'This leads to one of the more important ideas that has emerged in the past twenty years of hydrodynamic studies. Twenty years ago it seemed fairly safe to say that under certain extreme conditions hydrodynamic lubrication was not possible, and that only boundary sliding or even that metal/ metal contact must occur. It now seems that the hydrodynamic region extends very much further than was then considered likely. As Prof. H. Blok pointed out in his review paper, this type of 'marginal' 
hydrodynamic lubrication is largely due to the elastic deformation occurring at and around the contact regions. This makes it possible for hydrodynamic conditions to be carried over into a region where the lubricant film is extremely thin. Coupled with this new approach is the realization that it is no longer possible to treat the lubricant oil-even when it consists of a relatively pure single constituent-as a simple Newtonian fluid. The viscosity of the lubricant is affected by the temperature, by the rate of shear and by the pressure itself. These changes are not instantaneous, and the effect of pressure, for example, on viscosity and on density involves a relaxation time that may be of importance in highspeed sliding mechanisms. More basic work in this field is required and no doubt will be fortheoming in the near future. It would certainly seem that the next few years are likely to see further applications involving very thin-film 'marginal' hydrodynamic lubrication.

Friction and boundary lubrication. In this session it was apparent that great advances have been made since the discussion in 1937, not only in fundamental ideas but also in experimental techniques. In particular, as Dr. F. P. Bowden pointed out in his review paper on the friction of solids, electron microscopy has made it possible to examine the surface damage produced during sliding in very great detail, and recent experiments by Menter and others have even revealed the molecular array and dislocations present in crystalline solids. Whereas in 1937 there was little detailed understanding of the nature of contact between rubbing surfaces, it is now generally accepted that the real area of contact is usually a very minute fraction of the apparent geometrical area and that it is the detailed behaviour at these regions that determines the overall frictional properties of the solids. There is now a large body of evidence to suggest that the friction of metals is due in large measure to local adhesions. In addition, there may be appreciable ploughing of grooves in one surface by the other, so that there will be an additional ploughing term which must be considered. For unlubricated surfaces this is generally small and the main part of the friction arises from the shearing of the adhering junctions. A similar mechanism holds for non-metals, although in this case the deformation or ploughing term may be more important. This is particularly marked in the presence of surface films which can reduce the adhesion term, so that the work of deforming the surfaces may dominate the frictional behaviour. With elastic materials such as rubber the friction during lubricated sliding is largely due to elastic hysteresis losses in the rubber itself. Indeed, one of the new points that has recently emerged is the more general importance of elastic hysteresis losses in the friction and fatigue of sliding and rolling solids. Perhaps the most surprising feature is the extent to which a relatively simple physical picture can explain the frictional behaviour of solids as diverse as metals, diamond, rubber and wood.

Papers in this session included a number of detailed studies of the formation, deformation and subsequent breaking of the contact regions, their number, size and distribution, the extent of the adhesion at the interface, the effect of tangential displacements before macroscopic sliding occurs and the factors determining the occurrence of intermittent or 'stickslip' motion. Experiments with large-scale model friction-junctions were described which suggested how woar fragments might be produced during sliding. A new point of considerable interest was raised in a paper dealing with friction at extremely high sliding speeds - up to $2,000 \mathrm{ft}$./sec. The friction falls to a very low value due to melting of the surface layers by frictional heating. With some metals at very high speeds there is not sufficient time for plastic deformation to be propagated through the asperities. They behave in a brittle fashion and surface disintegration occurs. It would seem that the mechanism of friction and wear may be greatly modified at these extremely high speeds.

Boundary lubrication was not dealt with specifically in 1937 and in the present Conference most of the papers in this section dealt with the frictional behaviour of lamellar solids such as graphite, molybdenum disulphide and boron nitride. The gap was well bridged by Dr. C. B. Davies's review paper. He showed that the primary purpose of a boundary film is to reduce the amount of metallic welding across the sliding interface. To be most effective the film should be a solid of low shear strength and high resistance to penetration: and it should not be readily fluxed away by frictional heating because of melting, desorption, decomposition or oxidation. Fatty acids are most effective because of their ability to form metallic soaps at the surface, but these are melted or desorbed at temperatures above about $200^{\circ} \mathrm{C}$. Sodium soaps (or, in special applications, the addition of fillers) may extend the temperature-range, but in general for extreme temperatures other types of lubricant films must be used. The most common are the metal sulphides or chlorides formed by adding to the lubricant small quantities of compounds containing labile sulphur or chlorine. For still more extreme conditions films of lamellar solids are now being used, though here the basic technological difficulty appears to be that of obtaining good bonding to the surface. There is evidence that in some cases the metal oxide film is an important partner in the action of these and other boundary materials.

Bearings, ball bearings, and internal combustion engines. There were forty papers covering a rather wide range of miscellaneous problems on lubrication and wear, and these were dealt with in three sessions. Mr. P. P. Love reviewed papers dealing mainly with bearing materials, and pointed out that for mediumduty purposes no bearing alloy has been developed that is significantly better than the Babbitt metal patented in 1839. However, our understanding of the action of these and similar bearing materials has considerably advanced. Important factors are a relatively low melting point and a relatively low shear strength as well as resistance to corrosion and fatigue. It is also desirable that there should be an intrinsic anti-weld tendency between the bearing and the shaft, and here mutual solubility may play an important part. In recent years new bearing materials have been developed partly as a result of special bearing problems in the field of nuclear energy. Many of these can operate in the absence of liquid lubricants. They include bronzes and other hard materials impregnated with graphite, molybdenum disulphide and polytetrafluoroethylene; and plasties containing a variety of fillers. Surface treatments may be very effective either in the running-in process or even over more extended periods. The most widely discussed were surface treatments involving the use of lamellar solids. There was no paper dealing with the 'Sulf-Inuz' process for which astonishing claims have been made, but an interesting account was given of the action of phosphate coatings, which 
apparently function by enabling the high-spots to be removed safely during running in.

In the field of ball and roller bearings it was depressing to note how little fundamental research had been published by the bearing manufacturers themselves. As Mr. L. F. Hall pointed out in his review, most of the work has been carried out by national research organizations and by the larger engineering companies. The detailed behaviour of rolling elements in practice is still the subject of discussion: it is clear that at high speeds and low loads in the presence of oil lubricants they often operate under hydrodynamic conditions. In the presence of greases there is evidence that only a very small quantity adheres to the surface and that the bulk of the grease collects outside the the running parts in a state of complete immobility. This conclusion runs counter to the generally accepted view of grease lubrication. On the other hand there is now a better understanding of the factors involved in low-speed rolling, and for the first time there appears to be a sound analytical and experimental study available of the rolling and slipping of balls under elastic stresses. The mechanism of fatigue failure and pitting is still not fully understood and it seems that there is no single cause to which it can be attributed. Interesting problems arise in the lubrication of ball and roller bearings at very high temperatures in gas turbines. Many of these are concerned with corrosion and fatigue produced by the hot oxidizing atmosphere. It is a pity that no reference was made in this session to the promising results obtained by Cattaneo and his collaborators in the United States; they found that small quantities of sulphur in a reducing atmosphere can provide very effective high-temperature lubrication in the bearings of a running turbine.

Gear lubrication attracted attention from only a small number of contributors working directly with gears or with simulating mechanisms. This is a field in which there is still some difference of opinion as to whether hydrodynamic or boundary conditions prevail. This subject and the mechanisms of scuffing both merit further study.

A parallel session discussod the lubrication of internal combustion engines, the use of additives and other miscollaneous applications. It is now generally agreed that reducing the oil viscosity improves the performance of internal combustion engines, but there is elearly a limit to this. When corrosive wear in an ongine is important, it may be markedly reduced by increasing the alkalinity of the oil above a certain critical value. A development that could not have been envisaged in 1937 is the effect of nuclear radiation on lubricants. Apart from the danger of developing radioactivity if the oil contains sulphur additives, there is the general chemical deterioration which occurs. In his review Mr. J. G. Withers observed that although aromatics appear to be more stable to irradiation than other types of lubricants, this is not true of their thermal stability. Consequently, in assessing the viability of a lubricant the effect of both temperature and irradiation must be considered and more work in this field is required. Another contemporary problem is the lubrication of nuclear reactors in which liquid sodium is used as a heat-transfer medium. Surfaces which rub undor such a medium often suffer excessive wear or fatigue, and little is known in detail of the way in which this occurs or how it can be overcome.
A novel observation in machining investigations is that an electrical potential which opposes the thermal electromotive force developed during machining can increase the life of a tool two- or three-fold, an effect which is attributed to a suppression of the oxidation process. However, this is very recent work and more detailed study is needed.

Wear. A full day was devoted to a discussion of wear, and almost forty papers were summarized in a comprehensive review by Dr. F. T. Barwell. Here again there are new techniques available which shed considerable light on a number of aspects of wear that were obscure twenty years ago. These methods include oblique or taper sections for examining subsurface damage and metallurgical changes, highresolution interferometry for studying surface contours, micro-hardness tests for studying work hardening and phase transformations, electron microscopy for examining surface deformation on a fine scale, electron diffraction for studying surface structures and, in particular, radioactive isotopes which provide a beautiful means of studying the transfer and back-transfer processes that occur during wear.

The wear process is, of course, complex and many factors are involved. In some cases it may be purely mechanical, as in cavitation or impact, where failure probably occurs by cracking or by fatigue. It may be largely chemical as in corrosion, or a mixture of abrasive and chemical as in fretting. Probably the most common type of wear is that due to abrasion; the surfaces pluck fragments from one another as a result of strong adhesion at minute local regions of real contact, or hard fragmonts in one surface scrape or wipe away material from the other. Clearly in both mechanisms surface films can play an enormous part and it is generally true that lubricants are, in fact, used primarily to reduce wear and only secondarily to diminish friction. However, even if the adhesion and abrasion processes are reduced or ontirely eliminated, there is another effect due to the continued stressing of subsurface elements during repeated sliding. In some cases this may lead to fatigue and failure even though the surface itself is unworn.

Our understanding of the adhesion and abrasion processes themselves is now much more satisfactory than it was twenty years ago. Radioactive studies show that in some cases the plucked fragments are first oxidized and then wiped away, or they may coalesce and become larger fragments which are fatigued by repeated sliding and then poeled off the surface. Even in the presence of lubricants the basic mechanism is not greatly modified. Unfortunately the gap between such studies and real wear problems is a large and very real one. It consists of three parts. First, in a real machine there are multiple factors which may interact in a manner not foreseen from. simple laboratory experiments which can only deal with one or two variables at a time. There appears to be no short-term solution to this. Secondly, there is often a dominant factor in the practical problem which a theoretical study may completely overlook. A typical case is the wear of automobile crankshafts, which is generally eaused by metal particles or dirt particles embedded in the bearing material itself. Here tho basic frictional properties of the bearingshaft/lubricant combination are less important than the way in which these alien fragments are trapped and held in the bearing motal. Again, in the lubrication of cutting tools it is often the accessibility of the work to the lubricant that is at least as important 
as the intrinsic lubricating properties of the machining fluid. Here it would seem that the main onus lies on the technologist who studies the wear as it occurs in practice. The basic research worker can make a direct contribution to practice only if the practical man can indicate with some precision the main causes of failure. Thirdly, there is the general difficulty of assessing in the laboratory the severity of conditions to which a machine may, in practical operation, be subjected. In the discussion at this session it was pointed out, perhaps with some exaggeration, that in everyday affairs those who handle machinery occasionally behave more like gorillas than human beings: and it is during these simian interludes that the crucial damage is usually caused.
The gap between basic studies and practice is thus a large one which is still unbridged. The basic approach has provided many stimulating ideas, and the men of practical affairs have shown a high level of critical perception. What appears to be needed, apart from further efforts in both fields, is closer co-operation between these groups of workers. The Conference on Lubrication and Wear, which brought together engineers, chemists, physicists and metallurgists, should serve as a valuable guide in this direction. All those involved must be grateful to the organizing committe $\theta$ and to the administrative staff of the Institution of Mechanical Engineers for the vast amount of work and organizational skill that went into making the Conference a success.

D. TABOR

\section{NEWS and VIEWS}

\section{Sydney Young (1857-1937)}

THe youngest son of a prosperous Liverpool mer. chant, Sydney Young was born at Farnworth, near Widnes, in Lancashire, a century ago on December 29,1857 . He was educated at the Liverpool Royal Institution, at Owens College, Manchester, where he was a student of Sir Henry Roscoe and of Carl Schorlemmer, and at Strasbourg, where he studied under Rudolf Fittig with his life-long friends, Arthur Smithels and J. B. Cohen. He graduated at the University of London in 1880 and in 1882 became lecturer in chemistry under (Sir) William Ramsay at University College, Bristol. The next five years were the most productive in Young's career, for they witnessed his researches with Ramsay into the vapour pressures of solids and liquids and their thermodynamic relations which have become chemical classics. Their work on the critical constants convinced Young of the need for dealing with exceptionally pure substances. In Germany he had become an expert glass-blower, and with the aid of a most efficient 'bubbling still-head' he studied the nature of the lower-boiling fractions of American petroleum. In 1887 he succeeded Ramsay in the chair at Bristol, and in 1903 he became professor of chemistry at Trinity College, Dublin, where, however, his administrative and teaching duties seriously interfered with his experimental work. His most important books were "Fractional Distillation" (1903); "Stoichiometry" (1908, 2nd ed. 1918) ; and "Distillation, Principles and Processes", written in collaboration with six industrial specialists (1922). His scientific honours included fellowship of the Royal Society in 1893 , the presidency of the chemistry section of the British Association in 1904, the vice-presidency of the Chemical Society during 1917-20, and the presidency of the Royal Irish Academy during 1921-26. Young retired in 1928 and died in Bristol after a short illness on April 8, 1937, aged seventynine.

\section{Controlled Thermonuclear Reactions}

IN the House of Commons on December 10, the Prime Minister said that the progress of work on controlled thermonuclear reactions remained as explained by the Paymaster-General on November 11.
Promising results had been obtained with the experimental apparatus ZETA at Harwell, but the interpretation of these would take time. One aspect of the collaboration between Great Britain and the United States in research in this field was the adoption of common rules for the classification of information. If the proposals of a joint United States/United Kingdom Committee for the declassification of certain categories of information now under consideration were accepted, it would be possible to make public more details about work now proce日ding in both countries.

\section{Availability of Russian Scientific Literature}

The Parliamentary Secretary to the Ministry of Works, as representing the Lord President of the Council, was again questioned on Docember 10 regarding the translation of Russian scientific and technical literature, and said that many individual scientists with a knowledge of Russian are employed part-time on this work, and a small number, parttime, in Government scientific and technical research establishments. Government departments also use, on a contract basis, panels of translators outside the Government services. It is hoped to improve the availability of English translations of Russian literature. Mr. Nicholls then added a somewhat surprising remark to the effect that the aim should be to encourage more scientists to learn to read Russian. While no doubt a working knowledge of Russian, such as most scientists have of French and German, would be useful, this would not enable them to dispense with the services of specialist translators. Asked about the appointment of a scientist of scientific standing as scientific attache in Moscow, who in his own right would have access to Russian scientists, thus reducing the delay in making available the latest information about Russian developments, $\mathrm{Mr}$. Nicholls questioned whether any such appointment from Britain would be welcome without voluntary co-operation in the U.S.S.R. Earlier, Mr. Nicholls had stated that the appointment of a scientific attaché in Moscow is again being considered, and that he recognized the importance and urgency of the matter; he added that it is not quite correct to say that the Russians have a scientific attache in Britain. 